\title{
Turkish Endemic Achillea Species Protect Human Neuroblastoma SH-SY5Y Cells Against Hydrogen Peroxide-Induced Cytotoxicity ${ }^{\dagger}$
}

\author{
Kübra Uzun 1,* and Ayşe Kübra Karaboğa Arslan ${ }^{2}$ \\ 1 Department of Pharmacognosy, Faculty of Pharmacy, Erciyes University, 38039 Kayseri, Turkey \\ 2 Department of Pharmacology, Faculty of Pharmacy, Erciyes University, 38039 Kayseri, Turkey; \\ aysekubrakaraboga@gmail.com \\ * Correspondence: kubra1635@hotmail.com; Tel.: +90-352-207-6666 (ext. 28178) \\ + Presented at the 3rd International Conference on Natural Products for Cancer Prevention and Therapy, \\ Kayseri, Turkey, 18-20 December 2019.
}

Published: 9 January 2020

\begin{abstract}
The genus Achillea L. belongs to Asteraceae (Compositae), the largest family of vascular plants. There are 50 species, which of 24 is endemic in this genus in Turkey. Achillae species are used as a tonic, anti-inflammatory, anti-spasmodic, diaphoretic, diuretic and emmenagogic agents and have been used for treatment of hemorrhage, pneumonia, rheumatic pain and wounds healing traditionally. The imbalanced antioxidant systems leads to various pathophysiological conditions such as inflammation, neurodegenerative diseases and cancer. Achillea species have several components; essential oils, sesquiterpenes and phenolic compounds such as flavonoids and phenolic acids. Phenolic compounds and flavonoids are the most important medicinal metabolites of Achillea species. Flavonoids have been reported to exert a wide range of biological activities including anti-inflammatory, antioxidant and anti-tumor effects. This study aimed to assess the in vitro antioxidant properties of the methanol extracts from the aerial parts of A. cucullata (ACME) and $A$. sieheana (ASME) against hydrogen peroxide $\left(\mathrm{H}_{2} \mathrm{O}_{2}\right)$-induced oxidative stress in human SH-SY5Y neuronal cells. Our study showed that the ACME and ASME provided neuroprotection against $\mathrm{H}_{2} \mathrm{O}_{2}$-induced oxidative stress. In conclusion, ACME and ASME might help in reducing oxidative stress for preventive therapy associated with neurodegenerative diseases and cancer.
\end{abstract}

Keywords: Achillea sieheana; Achillea cucullata; cancer prevention; hydrogen peroxide

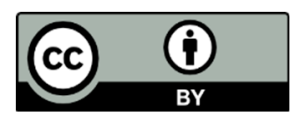

(C) 2020 by the authors. Licensee MDPI, Basel, Switzerland. This article is an open access article distributed under the terms and conditions of the Creative Commons Attribution (CC BY) license (http://creativecommons.org/licenses/by/4.0/). 